\title{
Twin's Birth-Order Differences in Height and Body Mass Index From Birth to Old Age : A Pooled Study of 26 Twin Cohorts Participating in the CODATwins Project
}

\section{Yokoyama, Yoshie}

2016-04

Yokoyama, Y, Jelenkovic , A , Sund , R , Sung , J , Hopper , J L , Ooki , S , Heikkila , K , Aaltonen, S , Tarnoki , A D , Tarnoki, D L, Willemsen, G, Bartels, M , van Beijsterveldt , T C E M , Saudino, K J , Cutler, T L, Nelson, T L, Whitfield, K E, Wardle, J, Llewellyn , C $H$, Fisher, $A, H e, M$, Ding , X, Bjerregaard-Andersen, $M$, Beck-Nielsen, H , Sodemann, M , Song , Y-M , Yang , S, Lee , K, Jeong , H-U, Knafo-Noam , A, Mankuta, D , Abramson, L, Burt , S A , Klump , K L , Ordonana , J R, Sanhez-Romera , J F , Colodro-Conde , L , Harris , J R, Brandt , I, Nilsen, T S , Craig , J M , Saffery , R, Ji , F , Ning , F , Pang , Z , Dubois , L, Boivin , M , Brendgen, M , Dionne , G , Vitaro , F , Martin , N G, Medland, S E, Montgomery, G W , Magnusson, P K E , Pedersen, N L, Aslan , A K D , Tynelius , P , Haworth , C M A , Plomin , R, Rebato , E , Rose , R J , Goldberg , J H , Rasmussen, F , Hur , Y-M , Sorensen , T I A , Boomsma , D I , Kaprio , J \& Silventoinen , K 2016 , ' Twin's Birth-Order Differences in Height and Body Mass Index From Birth to Old Age : A Pooled Study of 26 Twin Cohorts Participating in the CODATwins Project ' , Twin Research and Human Genetics , vol. 19 , no. 2 , pp. 112-124 . https://doi.org/10.1017/thg.2016.11

http://hdl.handle.net/10138/223935 https://doi.org/10.1017/thg.2016.11

publishedVersion

Downloaded from Helda, University of Helsinki institutional repository.

This is an electronic reprint of the original article.

This reprint may differ from the original in pagination and typographic detail.

Please cite the original version. 


\section{Twin's Birth-Order Differences in Height and Body Mass Index From Birth to Old Age: A Pooled Study of 26 Twin Cohorts Participating in the CODATwins Project}

Yoshie Yokoyama, ${ }^{1}$ Aline Jelenkovic, ${ }^{2,3}$ Reijo Sund, ${ }^{2}$ Joohon Sung, ${ }^{4,5}$ John L. Hopper, ${ }^{4,6}$ Syuichi Ooki, ${ }^{7}$ Kauko Heikkilä, ${ }^{8}$ Sari Aaltonen, ${ }^{2,8}$ Adam D. Tarnoki, ${ }^{9,10}$ David L. Tarnoki, ${ }^{9,10}$ Gonneke Willemsen, ${ }^{11}$ Meike Bartels, ${ }^{11}$ Toos C. E. M. van Beijsterveldt, ${ }^{11}$ Kimberly J. Saudino, ${ }^{12}$ Tessa L. Cutler, ${ }^{6}$ Tracy L. Nelson, ${ }^{13}$ Keith E. Whitfield, ${ }^{14}$ Jane Wardle, ${ }^{\dagger, 15}$ Clare H. Llewellyn, ${ }^{15}$ Abigail Fisher, ${ }^{15}$ Mingguang He, ${ }^{16,17}$ Xiaohu Ding, ${ }^{16}$ Morten Bjerregaard-Andersen, ${ }^{18,19,20}$ Henning Beck-Nielsen, ${ }^{20}$ Morten Sodemann, ${ }^{21}$ Yun-Mi Song, ${ }^{22}$ Sarah Yang, ${ }^{4,5}$ Kayoung Lee, ${ }^{23}$ Hoe-Uk Jeong, ${ }^{24}$ Ariel Knafo-Noam, ${ }^{25}$ David Mankuta, ${ }^{26}$ Lior Abramson, ${ }^{25}$ S. Alexandra Burt, ${ }^{27}$ Kelly L. Klump, ${ }^{27}$ Juan R. Ordoñana, ${ }^{28,29}$ Juan F. Sánchez-Romera, ${ }^{30,29}$ Lucia Colodro-Conde, ${ }^{28,31}$ Jennifer R. Harris, $^{32}$ Ingunn Brandt, ${ }^{32}$ Thomas Sevenius Nilsen, ${ }^{32}$ Jeffrey M. Craig, ${ }^{33,34}$ Richard Saffery, $^{33,34}$ Fuling Ji, $^{35}$ Feng Ning, ${ }^{35}$ Zengchang Pang, ${ }^{35}$ Lise Dubois, $^{36}$ Michel Boivin, ${ }^{37,38}$ Mara Brendgen, ${ }^{39}$ Ginette Dionne, ${ }^{37}$ Frank Vitaro, ${ }^{40}$ Nicholas G. Martin, ${ }^{41}$ Sarah E. Medland, ${ }^{41}$ Grant W. Montgomery, ${ }^{42}$

Patrik K. E. Magnusson, ${ }^{43}$ Nancy L. Pedersen, ${ }^{43}$ Anna K. Dahl Aslan, ${ }^{43,44}$ Per Tynelius, ${ }^{45}$ Claire M. A. Haworth, ${ }^{46}$ Robert Plomin, ${ }^{47}$ Esther Rebato, ${ }^{3}$ Richard J. Rose, ${ }^{48}$ Jack H. Goldberg, ${ }^{49}$ Finn Rasmussen, ${ }^{45}$ Yoon-Mi Hur, ${ }^{50}$ Thorkild I. A. Sørensen, ${ }^{51,46,52}$ Dorret I. Boomsma, ${ }^{11}$ Jaakko Kaprio, ${ }^{8,53,54}$ and Karri Silventoinen ${ }^{2,55}$

${ }^{1}$ Department of Public Health Nursing, Osaka City University, Osaka, Japan ${ }^{2}$ Department of Social Research, University of Helsinki, Helsinki, Finland ${ }^{3}$ Department of Genetics, Physical Anthropology and Animal Physiology, University of the Basque Country UPV/EHU, Leioa, Spain

${ }^{4}$ Department of Epidemiology, School of Public Health, Seoul National University, Seoul, Korea

5 Institute of Health and Environment, Seoul National University, Seoul, South-Korea

${ }^{6}$ The Australian Twin Registry, Centre for Epidemiology and Biostatistics, The University of Melbourne, Melbourne, Victoria, Australia

${ }^{7}$ Department of Health Science, Ishikawa Prefectural Nursing University, Kahoku, Ishikawa, Japan

${ }^{8}$ Department of Public Health, University of Helsinki, Helsinki, Finland

${ }^{9}$ Department of Radiology and Oncotherapy, Semmelweis University, Budapest, Hungary

${ }^{10}$ Hungarian Twin Registry, Budapest, Hungary

${ }^{11}$ Department of Biological Psychology, VU University Amsterdam, Amsterdam, the Netherlands

${ }^{12}$ Boston University, Department of Psychological and Brain Sciences, Boston, Massachusetts, USA

${ }^{13}$ Department of Health and Exercise Sciences and Colorado School of Public Health, Colorado State University, Fort Collins, Colorado, USA

${ }^{14}$ Psychology and Neuroscience, Duke University, Durham, North Carolina, USA

${ }^{15}$ Health Behaviour Research Centre, Department of Epidemiology and Public Health, Institute of Epidemiology and Health Care, University College London, London, UK

${ }^{16}$ State Key Laboratory of Ophthalmology, Zhongshan Ophthalmic Center, Sun Yat-sen University, Guangzhou, China

${ }^{17}$ Centre for Eye Research Australia, University of Melbourne, Melbourne, Victoria, Australia

${ }^{18}$ Bandim Health Project, INDEPTH Network, Bissau, Guinea-Bissau

${ }^{19}$ Research Center for Vitamins and Vaccines, Statens Serum Institute, Copenhagen, Denmark

${ }^{20}$ Department of Endocrinology, Odense University Hospital, Odense, Denmark

${ }^{21}$ Department of Infectious Diseases, Odense University Hospital, Odense, Denmark

RECEIVED 13 January 2016; ACCEPTED 4 February 2016.

ADDRESS FOR CORRESPONDENCE: Yoshie Yokoyama, Department of Public Health Nursing, Osaka City University, Osaka, Japan. E-mail: yyokoyama@nurs.osaka-cu.ac.jp

${ }^{\dagger}$ Deceased. 
${ }^{22}$ Department of Family Medicine, Samsung Medical Center, Sungkyunkwan University School of Medicine, Seoul, South-Korea

${ }^{23}$ Department of Family Medicine, Busan Paik Hospital, Inje University College of Medicine, Busan, Korea

${ }^{24}$ Department of Education, Mokpo National University, Jeonnam, South Korea

${ }^{25}$ The Hebrew University of Jerusalem, Jerusalem, Israel

${ }^{26}$ Hadassah Hospital Obstetrics and Gynecology Department, Hebrew University Medical School, Jerusalem, Israel

${ }^{27}$ Michigan State University, East Lansing, Michigan, USA

${ }^{28}$ Department of Human Anatomy and Psychobiology, University of Murcia, Murcia, Spain

${ }^{29}$ IMIB-Arrixaca, Murcia, Spain

${ }^{30}$ Department of Developmental and Educational Psychology, University of Murcia, Murcia, Spain

${ }^{31}$ OIMR Berghofer Medical Research Institute, Brisbane, Queensland, Australia

${ }^{32}$ Norwegian Institute of Public Health, Oslo, Norway

${ }^{33}$ Murdoch Childrens Research Institute, Royal Children's Hospital, Melbourne, Victoria, Australia

${ }^{34}$ Department of Paediatrics, University of Melbourne, Melbourne, Victoria, Australia

${ }^{35}$ Department of Noncommunicable Diseases Prevention, Qingdao Centers for Disease Control and Prevention, Qingdao, China

${ }^{36}$ School of Epidemiology, Public Health and Preventive Medicine, University of Ottawa, Ottawa, Ontario, Canada

${ }^{37}$ École de Psychologie, Université Laval, Québec, Canada

${ }^{38}$ Institute of Genetic, Neurobiological, and Social Foundations of Child Development, Tomsk State University, Russia

${ }^{39}$ Département de Psychologie, Université du Québec à Montréal, Montréal, Québec, Canada

${ }^{40}$ École de psychoéducation, Université de Montréal, Montréal, Québec, Canada

${ }^{41}$ Genetic Epidemiology Department, QIMR Berghofer Medical Research Institute, Brisbane, Queensland, Australia

${ }^{42}$ Molecular Epidemiology Department, QIMR Berghofer Medical Research Institute, Brisbane, Queensland, Australia

${ }^{43}$ Department of Medical Epidemiology and Biostatistics, Karolinska Institutet, Stockholm, Sweden

${ }^{44}$ Institute of Gerontology, School of Health Sciences, Jönköping University, Jönköping, Sweden

${ }^{45}$ Department of Public Health Sciences, Karolinska Institutet, Stockholm, Sweden

${ }^{46} \mathrm{MRC}$ Integrative Epidemiology Unit, University of Bristol, Bristol, UK

${ }^{47}$ King's College London, MRC Social, Genetic \& Developmental Psychiatry Centre, Institute of Psychiatry, Psychology \& Neuroscience, London, UK

${ }^{48}$ Indiana University Bloomington, Bloomington, Indiana, USA

${ }^{49}$ Department of Epidemiology, School of Public Health, University of Washington, Seattle, Washington, USA

${ }^{50}$ Department of Education, Mokpo National University, Jeonnam, South Korea

51 Institute of Preventive Medicine, Bispebjerg and Frederiksberg Hospitals, Copenhagen, The Capital Region, Denmark

${ }^{52}$ Novo Nordisk Foundation Centre for Basic Metabolic Research (Section on Metabolic Genetics), and Department of

Public Health, Faculty of Health and Medical Sciences, University of Copenhagen, Copenhagen, Denmark

${ }^{53}$ National Institute for Health and Welfare, Helsinki, Finland

${ }^{54}$ Institute for Molecular Medicine FIMM, Helsinki, Finland

${ }^{55}$ Osaka University Graduate School of Medicine, Osaka University, Osaka, Japan

We analyzed birth order differences in means and variances of height and body mass index (BMI) in monozygotic (MZ) and dizygotic (DZ) twins from infancy to old age. The data were derived from the international CODATwins database. The total number of height and BMI measures from 0.5 to 79.5 years of age was 397,466. As expected, first-born twins had greater birth weight than second-born twins. With respect to height, first-born twins were slightly taller than second-born twins in childhood. After adjusting the results for birth weight, the birth order differences decreased and were no longer statistically significant. First-born twins had greater BMI than the second-born twins over childhood and adolescence. After adjusting the results for birth weight, birth order was still associated with BMI until 12 years of age. No interaction effect between birth order and zygosity was found. Only limited evidence was found that birth order influenced variances of height or BMI. The results were similar among boys and girls and also in $\mathrm{MZ}$ and $\mathrm{DZ}$ twins. Overall, the differences in height and BMI between first- and second-born twins were modest even in early childhood, while adjustment for birth weight reduced the birth order differences but did not remove them for BMI.

Keywords: birth order, BMI, height, zygosity

It is well known that growth patterns of twins during the third trimester of pregnancy differ from those of singletons. In addition to having two fetuses in utero, there are twin-specific factors, such as birth order (Gielen et al., 2007; Glinianaia et al., 2000), zygosity (Buckler \& Green, 2008; Daw \& Walker, 1975; Loos et al., 2005), and chorionicity (Ananth et al., 1998; Bleker et al., 1979; Gielen et al., 2009; Gruenwald, 1970; Naeye et al., 1966; van Beijster- veldt et al., 2015) that are associated with intrauterine twin growth. Previous studies of twins have reported that the second-born twin is, on average, lighter than the first-born twin at birth (Gielen et al., 2007; Glinianaia et al., 2000; van Baal \& Boomsma, 1998). The factors determining birth order have a greater influence on birth weight than zygosity or chorionicity (Gielen et al., 2007; Sheay et al., 2004). 
The lower birth weight for second-born twins could be due to the fact that first-born twins have higher placental weights and more often have a central insertion of the umbilical cord, which are both positively correlated with birth weight. Possibly, first-born twins are also more optimally positioned with respect to nutrient intake (Gielen et al., 2006; Heinonen et al, 1996). In addition, previous studies have shown that first-born twins are, on average, taller and heavier than second-born twins until adolescence (Pietiläinen et al., 2002; Silventoinen et al., 2007). Second-born twins also have higher morbidity and mortality (Armson et al., 2006; Luo et al., 2014; Shinwell et al., 2004; Smith et al., 2007).

The persistence of the birth-order association suggests that prenatal factors can have long-lasting effects on body size. However, it is not known how these associations may change over the life course. Studies on age-dependent birth order differences in height and BMI are scarce, and small sample sizes make comparisons of the existing results difficult. Further, it is not known whether the factors behind birth order differences in height and BMI also induce variance differences. In this study, we aim to analyze birth-order differences in means and variances of height and BMI among MZ and DZ twins from infancy to old age and to test whether they can be explained by differences in birth weight. The data were derived from the large international CODATwins database, which was intended to collect together height and weight measurements from all twin cohorts in the world.

\section{Data and Methods}

In the CODATwins database (Silventoinen et al., 2015), there are 960,859 height and weight measures from twins at ages ranging from 0.5 to 103 years. Information on birth order, height, and weight measures were self-reported $(67 \%)$, parentally reported $(19 \%)$, or based on measures by nurses and clinicians (14\%). In this study, we included the following cohorts with information on birth order: Australian Twin Registry, Boston University Twin Project, Carolina African American Twin Study of Aging, FinnTwin12, FinnTwin16, Gemini Study, Guangzhou Twin Eye Study, Guinea-Bissau Twin Study, Hungarian Twin Registry, Japanese Twin Cohort, Korean Twin-Family Register, Longitudinal Israeli Study of Twins, Michigan Twins Study, Murcia Twin Registry, Norwegian Twin Registry, Peri/Postnatal Epigenetic Twins Study, Qingdao Twin Registry of Children, Quebec Newborn Twin Study, Queensland Twin Register, Swedish Young Male Twins Study of Adults, Swedish Young Male Twins Study of Children, South Korea Twin Registry, Swedish Twin Cohorts, Twins Early Developmental Study, West Japan Twins and Higher Order Multiple Births Registry and Young Netherlands Twin Registry. Height and weight measurement protocols, sample frames, and other basic information of these cohorts have been described elsewhere (Silventoinen et al., 2015). Age was classified into 1-year age groups from age 1 to 19 years (e.g., age 1 refers to $0.5-1.5$ years range), and 10-year age groups from age 20 to 79 years (e.g., 20-29 ..., and age 7079 years). Since the number of twin participants at 80 years of age or older was small, this group was excluded from the analyses.

In total, we had 429,587 height and BMI measurements at ages $0.5-79.5$ years with information on birth order. Additionally, we had information on birth weight from 107,782 twin individuals and birth length from 54,941 twin individuals. BMI was calculated as weight $(\mathrm{kg}) /$ square of height $\left(\mathrm{m}^{2}\right)$. Outliers were checked by visual inspection of histograms for each age and sex group. They were removed to obtain an approximately normal distribution of height, whereas the distribution of BMI was allowed to be positively skewed. The number of observations removed $(n=$ 1134) represented less than $0.3 \%$ of the whole database. We also excluded extreme birth length $(<25 \mathrm{~cm}$ or $>65 \mathrm{~cm})$ or birth weight $(<500 \mathrm{~g}$ or $>6000 \mathrm{~g})$ values. For the purpose of this study, we restricted the analyses to one observation per individual in each age group. The total number of height and BMI measures in this study was 397,466; in 307,606 of these cases we had information also on birth weight.

Equality of mean values between first- and second-born twins by zygosity, age group, and sex was tested using fixed effects regression analysis corrected for clustering of twin pairs. Equality of variances was tested using the Levene's clustered test based on the $10 \%$ trimmed mean (Iachine et al., 2010). This clustered version of the Levene's test is robust under the non-normality of outcomes. The interaction effects between zygosity and birth order were tested using Bonferroni correction of multiple testing with alpha level 0.0005 (0.05/100 tests). Percentage difference $(\%)$ between first- and second-born twins in mean values [(first born mean-second born mean)/second born mean] $* 100$ and standard deviations $(S D)$ [(first born $S D$-second born $S D) /$ second born $S D] * 100$ of height and BMI were calculated by sex. We also tested how the adjustment for birth weight affected the birth order difference on height and BMI in the cohorts having this information available using the fixed effects multiple regression model in each age groups. Statistical analyses were conducted using the Stata statistical software package (version 12.0; StataCorp, College Station, Texas, USA).

The pooled analysis was approved by the ethical board of the Department of Public Health, University of Helsinki. The data collections procedures of participating twin cohorts were approved by local ethical boards following the regulation in each country. Only anonymized data were delivered to the data management center at University of Helsinki. 


\section{TABLE 1}

\begin{tabular}{|c|c|c|c|c|c|c|c|c|c|c|c|c|}
\hline & & \multirow[b]{2}{*}{$\begin{array}{l}\text { Birth } \\
\text { order }\end{array}$} & \multicolumn{5}{|c|}{ Boys } & \multicolumn{5}{|c|}{ Girls } \\
\hline & & & $N$ & Mean & $\begin{array}{l}p \\
\text { value }^{a}\end{array}$ & $S D$ & $\begin{array}{l}p \\
\text { value }^{b}\end{array}$ & $N$ & Mean & $\begin{array}{l}p \\
\text { value }^{a}\end{array}$ & $S D$ & $\begin{array}{l}p \\
\text { value }^{\text {b }}\end{array}$ \\
\hline \multirow[t]{4}{*}{ Monozygotic twins } & Birth length & 1 & 5,304 & 47.0 & \multirow[t]{2}{*}{.002} & 3.58 & \multirow[t]{2}{*}{.001 } & 5,101 & 46.3 & \multirow{2}{*}{.132} & 3.58 & \multirow[t]{2}{*}{.085} \\
\hline & & 2 & 5,293 & 46.8 & & 3.69 & & 5,070 & 46.2 & & 3.64 & \\
\hline & Birth weight $(\mathrm{kg})$ & 1 & 9,617 & 2.54 & \multirow[t]{2}{*}{$<.001$} & 0.56 & \multirow[t]{2}{*}{.067 } & 10,383 & 2.43 & \multirow[t]{2}{*}{$<.001$} & 0.54 & \multirow[t]{2}{*}{$<.001$} \\
\hline & & 2 & 9,524 & 2.51 & & 0.57 & & 10,330 & 2.39 & & 0.55 & \\
\hline \multirow[t]{4}{*}{ Dizygotic twins } & Birth length & 1 & 9,160 & 47.4 & \multirow[t]{2}{*}{.207} & 3.55 & \multirow[t]{2}{*}{.009} & 7,967 & 46.8 & \multirow[t]{2}{*}{.191} & 3.60 & \multirow[t]{2}{*}{.018} \\
\hline & & 2 & 8,914 & 47.4 & & 3.65 & & 8,132 & 46.7 & & 3.64 & \\
\hline & Birth weight $(\mathrm{kg})$ & 1 & 17,468 & 2.63 & \multirow[t]{2}{*}{$<.001$} & 0.57 & \multirow[t]{2}{*}{.005} & 16,562 & 2.53 & \multirow[t]{2}{*}{$<.001$} & 0.55 & \multirow[t]{2}{*}{.001} \\
\hline & & 2 & 17,098 & 2.58 & & 0.58 & & 16,800 & 2.47 & & 0.56 & \\
\hline
\end{tabular}

Note: $p$ value ${ }^{a}=p$ value for equality of means; $p$ value ${ }^{b}=p$ value for equality of variances; $S D=$ standard deviation.

\section{Results}

Table 1 provides the mean birth length and birth weight according to birth order, sex, and zygosity. In MZ twins, the first-born male twins had greater length than the secondborn male twins. However, in DZ twins, average birth length was not significantly different between the first-born and the second-born twins. In MZ and DZ twins, the firstborn twins had greater birth weight than the second-born twins. The standard deviations of birth weight in the firstborn and the second-born twins in $\mathrm{MZ}$ and $\mathrm{DZ}$ twins were significantly different except in MZ boys.

Descriptive statistics by birth order, age, and sex in $\mathrm{MZ}$ and DZ twins are presented in Tables 2 and 3 for height, respectively. Sample size for each birth order, age, and sex group ranged between 421 and 5,407 individuals from age 1 through 19 years, and between 117 and 4,398 individuals in adulthood ( $\geq 20$ years). The 6 and $\geq 70$-year age groups in $\mathrm{MZ}$ twins had the smallest sample sizes. In $\mathrm{MZ}$ twins, significantly taller height in the first-born than in the second-born twins were observed at the age of $1,2,5,8$, and 10 years in men and from the age of 1 to 3,7 , and 12 years in women (Table 2). However, in DZ twins, average height was not significantly different between the first-born and the second-born twins (Table 3). The standard deviations of height in the first-born and the second-born twins in $\mathrm{MZ}$ and DZ twin were not significantly different in the majority of age groups. Results were similar in men and women.

Tables 4 and 5 show the respective results for BMI. The sample sizes are same as for height. In MZ twins, the firstborn twins had greater BMI than the second-born twins except the 18 and $\geq 50$-year age groups in men, and the 40 to 49 -year age group in women. Statistical significance was attained in the majority of age groups until the 12 years age groups (Table 4). In DZ twins, first-borns had greater BMI than the second-born twins except the 14- and 60to 69-years-old men. The differences were also statistically significant particularly until 5 years of age. The standard deviations of BMI in the first-born and the second-born twins in MZ twins were not significantly different. However, the standard deviations of BMI in the first-born and the second-born twins in DZ twins were significantly different at the age of $1,3,10,15,17$, and 18 years in men, and the age of 16, 18, and 20-29 years in women (Table 5).

Because the interaction effects between birth order and zygosity were not statistically significant after Bonferroni correction for height or BMI (nominal $p$ values .047-.008), data from $\mathrm{MZ}$ and $\mathrm{DZ}$ twins were combined in the further analyses. Figure 1 illustrates the percentage difference (\%) in the mean and standard deviation of height between the first-born and the second-born twins in men and women in the pooled data of $\mathrm{MZ}$ and $\mathrm{DZ}$ twins. Figure 2 presents the same results for BMI. Both for height and BMI, the first-born twins almost always showed higher mean values than the second-born twins. The mean differences in height between the first-born and the second-born twins ranged from $-0.1 \%$ to $0.3 \%$ in men (at the age of 15 years and 5 years) and from $-0.3 \%$ to $0.4 \%$ in women (at the 15 and $\geq 70$-year age groups). The first-born male twins presented up to $1.4 \%$ greater BMI than the second-born male twins until 17 years of age and decreased with age in adulthood. The mean differences between the first-born and the second-born twins ranged from $0.2 \%$ to $1.4 \%$ in women (at the age of 15 years and 18 years). For standard deviation, the differences were small and did not show any systematic pattern varying from negative to positive.

Table 6 shows the results of fixed effects regression analysis of height and BMI at each age in the sub-cohort with information on birth weight. Adjustment for birth weight decreased the birth order differences in height and BMI. After adjusting for birth weight, birth order was associated with height at the age of $1,3,5,7$, and 10 years in men, whereas birth order was not associated with height in women. Moreover, after adjusting for birth weight, birth order was associated with BMI from the age of 1 to $5,7,10$, 11 , and 12 years in men, and from the age of 1 to $5,7,10$, and 12 years in women.

\section{Discussion}

The CODATwins study established a database with data on body size from twin cohorts in different countries from 
TABLE 2

Number of Twin Individuals, Mean and Standard Deviation of Height $(\mathrm{cm})$ by Birth Order, Age, and Sex in Monozygotic Twins

\begin{tabular}{|c|c|c|c|c|c|c|c|c|c|c|c|}
\hline & \multirow[b]{2}{*}{ Birth order } & \multicolumn{5}{|c|}{ Men } & \multicolumn{5}{|c|}{ Women } \\
\hline & & $N$ & Mean & $p$ value ${ }^{a}$ & $S D$ & $p$ value ${ }^{b}$ & $N$ & Mean & $p$ value ${ }^{a}$ & $S D$ & $p$ value ${ }^{b}$ \\
\hline \multirow[t]{2}{*}{ Age 1} & 1 & 2,843 & 73.6 & .029 & 4.54 & 0.176 & 2,994 & 72.4 & 0.014 & 4.55 & .267 \\
\hline & 2 & 2,838 & 73.5 & & 4.59 & & 2,991 & 72.3 & & 4.55 & \\
\hline \multirow[t]{2}{*}{ Age 2} & 1 & 2,310 & 86.5 & .121 & 4.41 & 0.047 & 2,339 & 85.4 & 0.020 & 4.42 & .307 \\
\hline & 2 & 2,293 & 86.4 & & 4.46 & & 2,323 & 85.3 & & 4.44 & \\
\hline \multirow[t]{2}{*}{ Age 3} & 1 & 2,830 & 95.8 & .044 & 4.45 & 0.264 & 3,140 & 94.9 & 0.002 & 4.39 & .775 \\
\hline & 2 & 2,834 & 95.7 & & 4.47 & & 3,125 & 94.8 & & 4.38 & \\
\hline \multirow[t]{2}{*}{ Age 4} & 1 & 1,600 & 102.1 & .18 & 5.17 & 0.045 & 1,594 & 101.0 & 0.116 & 5.13 & .118 \\
\hline & 2 & 1,588 & 101.9 & & 5.33 & & 1,595 & 100.9 & & 5.29 & \\
\hline \multirow[t]{2}{*}{ Age 5} & 1 & 1,272 & 110.8 & .018 & 5.91 & 0.770 & 1,341 & 110.2 & 0.299 & 6.16 & .496 \\
\hline & 2 & 1,266 & 110.7 & & 5.93 & & 1,328 & 110.1 & & 6.06 & \\
\hline \multirow{2}{*}{ Age 6} & 1 & 528 & 114.1 & .279 & 6.45 & 0.856 & 427 & 112.9 & 0.834 & 5.66 & .180 \\
\hline & 2 & 512 & 113.7 & & 6.40 & & 421 & 112.9 & & 5.88 & \\
\hline \multirow{2}{*}{ Age 7} & 1 & 2,345 & 123.6 & .216 & 6.62 & 0.134 & 2,540 & 122.9 & 0.020 & 6.49 & .973 \\
\hline & 2 & 2,330 & 123.5 & & 6.72 & & 2,536 & 122.8 & & 6.53 & \\
\hline \multirow[t]{2}{*}{ Age 8} & 1 & 1,057 & 127.6 & .016 & 6.35 & 0.322 & 1,020 & 127.0 & 0.077 & 6.42 & .209 \\
\hline & 2 & 1,042 & 127.4 & & 6.23 & & 1,021 & 126.8 & & 6.56 & \\
\hline \multirow{2}{*}{ Age 9} & 1 & 1,042 & 133.0 & .143 & 6.97 & 0.509 & 1,005 & 132.0 & 0.232 & 6.93 & .590 \\
\hline & 2 & 997 & 132.8 & & 7.04 & & 986 & 131.8 & & 6.92 & \\
\hline \multirow[t]{2}{*}{ Age 10} & 1 & 1,988 & 140.0 & .044 & 7.18 & 0.737 & 2,088 & 139.8 & 0.115 & 7.41 & .199 \\
\hline & 2 & 1,924 & 139.9 & & 7.19 & & 2,048 & 139.7 & & 7.47 & \\
\hline \multirow{2}{*}{ Age 11} & 1 & 1,530 & 143.4 & .470 & 7.15 & 0.959 & 1,588 & 144.2 & 0.180 & 7.30 & .003 \\
\hline & 2 & 1,470 & 143.3 & & 7.12 & & 1,530 & 144.0 & & 7.48 & \\
\hline \multirow[t]{2}{*}{ Age 12} & 1 & 2,032 & 151.4 & .434 & 8.30 & 0.884 & 2,127 & 152.3 & 0.036 & 8.01 & .030 \\
\hline & 2 & 1,955 & 151.3 & & 8.24 & & 2,053 & 152.1 & & 8.18 & \\
\hline \multirow[t]{2}{*}{ Age 13} & 1 & 692 & 157.9 & .693 & 9.30 & 0.301 & 642 & 157.3 & 0.269 & 7.40 & .494 \\
\hline & 2 & 620 & 157.6 & & 9.39 & & 591 & 157.2 & & 7.54 & \\
\hline \multirow[t]{2}{*}{ Age 14} & 1 & 1,328 & 165.4 & .815 & 8.95 & 0.808 & 1,497 & 161.8 & 0.441 & 6.68 & .066 \\
\hline & 2 & 1,280 & 165.4 & & 9.09 & & 1,468 & 161.8 & & 6.85 & \\
\hline Age 15 & 1 & 658 & 171.5 & .433 & 8.68 & 0.968 & 639 & 164.5 & 0.615 & 7.32 & .029 \\
\hline & 2 & 639 & 171.7 & & 8.70 & & 606 & 165.1 & & 7.00 & \\
\hline Age 16 & 1 & 1,074 & 175.5 & .731 & 7.61 & 0.546 & 1,311 & 164.4 & 0.398 & 6.56 & .067 \\
\hline & 2 & 1,028 & 175.5 & & 7.56 & & 1,257 & 164.5 & & 6.34 & \\
\hline Age 17 & 1 & 1,100 & 177.7 & .315 & 7.29 & 0.608 & 1,411 & 165.6 & 0.710 & 6.62 & .601 \\
\hline & 2 & 1,074 & 177.8 & & 7.47 & & 1,388 & 165.8 & & 6.59 & \\
\hline Age 18 & 1 & 1,253 & 178.9 & .207 & 7.05 & 0.085 & 826 & 166.1 & 0.450 & 6.48 & .495 \\
\hline & 2 & 1,253 & 178.9 & & 6.89 & & 812 & 166.1 & & 6.64 & \\
\hline Age 19 & 1 & 639 & 179.2 & .345 & 7.04 & 0.250 & 717 & 166.1 & 0.255 & 6.98 & .279 \\
\hline & 2 & 607 & 179.3 & & 6.85 & & 702 & 165.9 & & 6.83 & \\
\hline Age $20-29$ & 1 & 2,890 & 179.2 & .117 & 6.90 & 0.412 & 3,488 & 164.5 & 0.881 & 6.50 & .839 \\
\hline & 2 & 2,878 & 179.0 & & 6.98 & & 3,478 & 164.6 & & 6.47 & \\
\hline Age $30-39$ & 1 & 2,305 & 178.1 & .360 & 7.04 & 0.494 & 3,378 & 164.0 & 0.233 & 6.67 & .554 \\
\hline & 2 & 2,290 & 177.9 & & 6.92 & & 3,349 & 164.0 & & 6.62 & \\
\hline Age 40-49 & 1 & 1,420 & 177.2 & .295 & 7.04 & 0.370 & 1,886 & 163.2 & 0.924 & 6.65 & .436 \\
\hline & 2 & 1,355 & 177.1 & & 7.03 & & 1,844 & 163.1 & & 6.58 & \\
\hline Age $50-59$ & 1 & 1,038 & 176.4 & .805 & 7.02 & 0.181 & 1,601 & 162.5 & 0.613 & 6.50 & .047 \\
\hline & 2 & 1,029 & 176.3 & & 7.22 & & 1,609 & 162.4 & & 6.70 & \\
\hline Age 60-69 & 1 & 506 & 174.9 & .386 & 6.40 & 0.006 & 880 & 161.7 & 0.660 & 6.30 & .297 \\
\hline & 2 & 494 & 174.4 & & 6.99 & & 878 & 161.9 & & 6.47 & \\
\hline Age $70-79$ & 1 & 126 & 173.7 & .412 & 7.09 & 0.199 & 273 & 161.3 & 0.378 & 6.91 & .162 \\
\hline & 2 & 117 & 173.1 & & 7.48 & & 268 & 160.8 & & 6.61 & \\
\hline
\end{tabular}

Note: $p$ value $e^{a}=p$ value for equality of means; $p$ value ${ }^{b}=p$ value for equality of variances; $S D=$ standard deviation.

infancy to old age. Previous studies in twins have reported that the second-born twin was lighter than the first-born twin at birth (Gielen et al., 2007; Glinianaia et al., 2000) and our results from this very large international database are consistent with these studies. First-born twins were slightly taller than second-born twins in MZ pairs at some ages until 12 years of age. After adjustment for birth weight, birth order was associated with height in males only at some ages until 10 years of age. We did not find any strong evidence that birth order differences varied according to zygosity since the interaction effects between zygosity and birth order were not statistically significant after Bonferroni correction. These results suggest that birth order has a slight influence on height in twins during childhood, mainly explained by birth weight.

Meanwhile, the current study revealed birth order differences in mean BMI until 12 years of age in MZ pairs, and in mean values of BMI until 5 years of age in DZ twin pairs. These birth order differences in mean values of BMI were generally modest but still statistically significant. Adjustment for birth weight reduced these differences, but a significant association of birth order with BMI remained 
TABLE 3

Number of Twin Individuals, Mean and Standard Deviation of Height $(\mathrm{cm})$ by Birth Order, Age, and Sex in Dizygotic Twins

\begin{tabular}{|c|c|c|c|c|c|c|c|c|c|c|c|}
\hline & \multirow[b]{2}{*}{ Birth order } & \multicolumn{5}{|c|}{ Men } & \multicolumn{5}{|c|}{ Women } \\
\hline & & $N$ & Mean & $p$ value ${ }^{a}$ & $S D$ & $p$ value ${ }^{b}$ & $N$ & Mean & $p$ value ${ }^{a}$ & $S D$ & $p$ value ${ }^{b}$ \\
\hline \multirow[t]{2}{*}{ Age 1} & 1 & 5,088 & 74.8 & .051 & 4.11 & .531 & 4,759 & 73.4 & .113 & 4.06 & .359 \\
\hline & 2 & 4,962 & 74.6 & & 4.11 & & 4,821 & 73.2 & & 4.14 & \\
\hline \multirow[t]{2}{*}{ Age 2} & 1 & 4,184 & 87.4 & .340 & 4.22 & .265 & 3,815 & 86.3 & .141 & 4.34 & .189 \\
\hline & 2 & 4,102 & 87.2 & & 4.28 & & 3,871 & 86.1 & & 4.27 & \\
\hline \multirow[t]{2}{*}{ Age 3} & 1 & 5,407 & 96.6 & .074 & 4.43 & .822 & 5,085 & 95.6 & .159 & 4.55 & .257 \\
\hline & 2 & 5,266 & 96.4 & & 4.42 & & 5,208 & 95.4 & & 4.62 & \\
\hline \multirow[t]{2}{*}{ Age 4} & 1 & 2,993 & 102.4 & .873 & 5.27 & .872 & 2,818 & 101.3 & .745 & 5.21 & .119 \\
\hline & 2 & 2,954 & 102.5 & & 5.31 & & 2,848 & 101.1 & & 5.25 & \\
\hline \multirow[t]{2}{*}{ Age 5} & 1 & 2,349 & 112.0 & .126 & 6.07 & .478 & 2,099 & 111.1 & .143 & 6.37 & .602 \\
\hline & 2 & 2,259 & 111.5 & & 6.13 & & 2,189 & 110.7 & & 6.41 & \\
\hline \multirow[t]{2}{*}{ Age 6} & 1 & 583 & 114.5 & .819 & 6.88 & .311 & 455 & 114.2 & .261 & 7.55 & .180 \\
\hline & 2 & 552 & 114.8 & & 7.15 & & 469 & 113.6 & & 7.39 & \\
\hline \multirow{2}{*}{ Age 7} & 1 & 3,986 & 124.8 & .232 & 6.59 & .266 & 3,877 & 123.8 & .359 & 6.71 & .239 \\
\hline & 2 & 3,981 & 124.5 & & 6.72 & & 3,864 & 123.8 & & 6.65 & \\
\hline Age 8 & 1 & 1,478 & 129.2 & .533 & 6.42 & .154 & 1,279 & 128.3 & .192 & 6.82 & .721 \\
\hline \multirow{2}{*}{ Age 9} & 1 & 1,445 & 134.5 & .664 & 7.30 & .271 & 1,354 & 133.9 & .994 & 7.25 & .830 \\
\hline & 2 & 1,449 & 134.2 & & 7.14 & & 1,316 & 133.9 & & 7.38 & \\
\hline \multirow[t]{2}{*}{ Age 10} & 1 & 3,171 & 141.8 & .097 & 7.02 & .226 & 2,994 & 141.2 & .578 & 7.35 & .539 \\
\hline & 2 & 3,148 & 141.4 & & 7.21 & & 2,973 & 141.0 & & 7.39 & \\
\hline \multirow[t]{2}{*}{ Age 11} & 1 & 2,385 & 145.2 & .130 & 7.23 & .505 & 2,146 & 145.1 & .691 & 7.77 & .279 \\
\hline & 2 & 2,288 & 144.6 & & 7.41 & & 2,153 & 145.4 & & 7.92 & \\
\hline \multirow[t]{2}{*}{ Age 12} & 1 & 3,152 & 152.5 & .945 & 7.82 & .617 & 3,031 & 153.3 & .813 & 8.36 & .444 \\
\hline & 2 & 3,021 & 152.3 & & 7.92 & & 3,048 & 153.3 & & 8.24 & \\
\hline \multirow[t]{2}{*}{ Age 13} & 1 & 1,035 & 158.8 & .887 & 8.77 & .051 & 898 & 158.4 & .938 & 7.80 & .964 \\
\hline & 2 & 965 & 158.7 & & 9.36 & & 896 & 158.7 & & 7.98 & \\
\hline \multirow[t]{2}{*}{ Age 14} & 1 & 2,353 & 165.6 & .888 & 8.94 & .031 & 2,332 & 162.8 & .358 & 6.74 & .529 \\
\hline & 2 & 2,266 & 165.8 & & 8.62 & & 2,370 & 162.5 & & 6.87 & \\
\hline Age 15 & 1 & 1,143 & 172.2 & .878 & 8.84 & .729 & 1,042 & 165.4 & .547 & 7.18 & .358 \\
\hline & 2 & 1,078 & 172.3 & & 8.87 & & 1,013 & 165.7 & & 7.03 & \\
\hline Age 16 & 1 & 1,990 & 176.0 & .855 & 7.52 & .827 & 2,086 & 165.4 & .952 & 6.61 & .174 \\
\hline & 2 & 1,940 & 175.8 & & 7.46 & & 2,090 & 165.5 & & 6.43 & \\
\hline Age 17 & 1 & 2,159 & 178.5 & .317 & 7.30 & .415 & 2,230 & 166.4 & .758 & 6.32 & .035 \\
\hline Age 19 & 1 & 1,044 & 180.4 & .973 & 6.72 & .362 & 1,099 & 167.2 & .662 & 6.60 & .187 \\
\hline & 2 & 1,049 & 179.8 & & 6.86 & & 1,047 & 167.3 & & 6.47 & \\
\hline Age $20-29$ & 1 & 4,036 & 179.9 & .191 & 6.69 & .624 & 4,398 & 165.8 & .255 & 6.56 & .167 \\
\hline & 2 & 4,121 & 179.4 & & 6.74 & & 4,270 & 165.5 & & 6.50 & \\
\hline Age $30-39$ & 1 & 3,221 & 179.2 & .674 & 6.82 & .209 & 4,120 & 165.2 & .594 & 6.58 & .069 \\
\hline & 2 & 3,351 & 178.9 & & 6.64 & & 3,887 & 165.0 & & 6.43 & \\
\hline Age $40-49$ & 1 & 2,403 & 178.9 & .791 & 6.69 & .775 & 2,877 & 164.6 & .836 & 6.36 & .961 \\
\hline & 2 & 2,411 & 178.9 & & 6.70 & & 2,775 & 164.9 & & 6.33 & \\
\hline Age $50-59$ & 1 & 2,678 & 178.0 & .532 & 6.73 & .281 & 3,261 & 164.1 & .898 & 6.20 & .081 \\
\hline & 2 & 2,634 & 177.7 & & 6.56 & & 3,086 & 164.3 & & 6.05 & \\
\hline Age $60-69$ & 1 & 1,265 & 175.9 & .927 & 6.73 & .657 & 1,560 & 162.9 & .813 & 6.13 & .280 \\
\hline & 2 & 1,276 & 175.8 & & 6.85 & & 1,532 & 162.9 & & 6.27 & \\
\hline Age $70-79$ & 1 & 310 & 175.3 & .586 & 6.53 & .287 & 435 & 162.1 & .543 & 6.78 & .064 \\
\hline & 2 & 329 & 175.0 & & 6.82 & & 390 & 161.4 & & 6.05 & \\
\hline
\end{tabular}

Note: $p$ value ${ }^{a}=p$ value for equality of means; $p$ value ${ }^{b}=p$ value for equality of variances; $S D=$ standard deviation.

until 12 years of age. Jelenkovic et al. (2015) reported that DZ twins are consistently taller than MZ twins, but mean $\mathrm{BMI}$ is not significantly different between $\mathrm{MZ}$ and DZ twins at young ages. Based on our study, birth order difference seems to associate more strongly with BMI than zygosity difference. For standard deviations of height and BMI, the results were not statistically significant and did not show any systematic pattern either. Thus, it seems that the factors behind the mean differences between first-born and second-born twins were not associated with variances.

According to the Developmental Origins of Health and Disease hypothesis, birth weight is associated with disease risk later in life and is a determinant of adult health (Barker, 1998; Brodsky \& Christou, 2004). This appears more salient for twins, who are born earlier and weigh less as compared to singletons (Loos et al., 2005). However, it has been indicated that growth of twins is not equal to growth of singletons after 29 weeks of gestation (Loos et al., 2005), and the optimal intrauterine growth and lowest morbidity is achieved earlier in gestation for twins than for singletons (Luke et al., 1993; Soucie et al., 2006). In addition, previous studies in twins have reported that the second-born twin was lighter than the first-born twin at birth (Gielen et al., 2007; Glinianaia et al., 2000). Moreover, low birth weight predicts lower adult 
TABLE 4

Number of Twin Individuals, Mean and Standard Deviation of Birth Weight $(\mathrm{kg})$ and BMI $\left(\mathrm{kg} / \mathrm{m}^{2}\right)$ by Birth Order, Age, and Sex in Monozygotic Twins

\begin{tabular}{|c|c|c|c|c|c|c|c|c|c|c|c|}
\hline & \multirow[b]{2}{*}{ Birth order } & \multicolumn{5}{|c|}{ Men } & \multicolumn{5}{|c|}{ Women } \\
\hline & & $N$ & Mean & $p$ value $^{a}$ & $S D$ & $p$ value ${ }^{b}$ & $N$ & Mean & $p$ value $^{a}$ & $S D$ & $p$ value ${ }^{b}$ \\
\hline \multirow[t]{2}{*}{ Age 1} & 1 & 2,843 & 17.21 & $<.001$ & 1.41 & .798 & 2,994 & 16.84 & $<.001$ & 1.42 & .755 \\
\hline & 2 & 2,838 & 17.11 & & 1.42 & & 2,991 & 16.74 & & 1.42 & \\
\hline \multirow[t]{2}{*}{ Age 2} & 1 & 2,310 & 16.62 & $<.001$ & 1.40 & .921 & 2,339 & 16.17 & $<.001$ & 1.38 & .915 \\
\hline & 2 & 2,293 & 16.51 & & 1.39 & & 2,323 & 16.04 & & 1.38 & \\
\hline \multirow[t]{2}{*}{ Age 3} & 1 & 2,830 & 16.02 & $<.001$ & 1.41 & .276 & 3,140 & 15.68 & $<.001$ & 1.50 & .217 \\
\hline & 2 & 2,834 & 15.88 & & 1.39 & & 3,125 & 15.58 & & 1.47 & \\
\hline \multirow{2}{*}{ Age 4} & 1 & 1,600 & 15.90 & .023 & 1.78 & .506 & 1,594 & 15.71 & .001 & 2.01 & .355 \\
\hline & 2 & 1,588 & 15.84 & & 1.81 & & 1,595 & 15.59 & & 1.98 & \\
\hline \multirow[t]{2}{*}{ Age 5} & 1 & 1,272 & 15.34 & $<.001$ & 1.54 & .671 & 1,341 & 15.13 & $<.001$ & 1.64 & .360 \\
\hline & 2 & 1,266 & 15.20 & & 1.51 & & 1,328 & 15.01 & & 1.64 & \\
\hline \multirow[t]{2}{*}{ Age 6} & 1 & 528 & 15.54 & .265 & 1.77 & .735 & 427 & 15.25 & .084 & 1.76 & .735 \\
\hline & 2 & 512 & 15.48 & & 1.77 & & 421 & 15.14 & & 1.74 & \\
\hline \multirow[t]{2}{*}{ Age 7} & 1 & 2,345 & 15.40 & .002 & 1.69 & .419 & 2,540 & 15.44 & $<.001$ & 1.93 & .314 \\
\hline & 2 & 2,330 & 15.31 & & 1.71 & & 2,536 & 15.31 & & 1.93 & \\
\hline \multirow[t]{2}{*}{ Age 8} & 1 & 1,057 & 15.64 & .026 & 1.72 & .331 & 1,020 & 15.65 & $<.001$ & 1.97 & .240 \\
\hline & 2 & 1,042 & 15.54 & & 1.67 & & 1,021 & 15.50 & & 1.93 & \\
\hline \multirow[t]{2}{*}{ Age 9} & 1 & 1,042 & 16.29 & .057 & 2.10 & .318 & 1,005 & 16.33 & .152 & 2.38 & .556 \\
\hline & 2 & 997 & 16.23 & & 2.17 & & 986 & 16.22 & & 2.39 & \\
\hline \multirow[t]{2}{*}{ Age 10} & 1 & 1,988 & 16.64 & .005 & 2.30 & .042 & 2,088 & 16.67 & $<.001$ & 2.45 & .502 \\
\hline & 2 & 1,924 & 16.54 & & 2.17 & & 2,048 & 16.56 & & 2.40 & \\
\hline \multirow[t]{2}{*}{ Age 11} & 1 & 1,530 & 17.32 & $<.001$ & 2.56 & .004 & 1,588 & 17.37 & .035 & 2.72 & .374 \\
\hline & 2 & 1,470 & 17.10 & & 2.44 & & 1,530 & 17.30 & & 2.80 & \\
\hline \multirow[t]{2}{*}{ Age 12} & 1 & 2,032 & 17.87 & $<.001$ & 2.72 & .197 & 2,127 & 17.92 & $<.001$ & 2.74 & .999 \\
\hline & 2 & 1,955 & 17.72 & & 2.67 & & 2,053 & 17.77 & & 2.71 & \\
\hline \multirow[t]{2}{*}{ Age 13} & 1 & 692 & 18.45 & .092 & 2.89 & .051 & 642 & 18.94 & .094 & 3.19 & .383 \\
\hline & 2 & 620 & 18.30 & & 2.79 & & 591 & 18.82 & & 3.27 & \\
\hline \multirow[t]{2}{*}{ Age 14} & 1 & 1,328 & 19.28 & .132 & 2.86 & .422 & 1,497 & 19.67 & .007 & 3.02 & .956 \\
\hline & 2 & 1,280 & 19.23 & & 2.82 & & 1,468 & 19.59 & & 3.01 & \\
\hline Age 15 & 1 & 658 & 19.64 & .194 & 2.92 & .416 & 639 & 19.95 & .168 & 3.20 & .503 \\
\hline & 2 & 639 & 19.59 & & 2.93 & & 606 & 19.80 & & 3.15 & \\
\hline Age 16 & 1 & 1,074 & 20.68 & .138 & 2.99 & .106 & 1,311 & 20.64 & .098 & 2.98 & .172 \\
\hline & 2 & 1,028 & 20.55 & & 2.87 & & 1,257 & 20.57 & & 2.95 & \\
\hline Age 17 & 1 & 1,100 & 20.94 & .387 & 2.72 & .850 & 1,411 & 20.73 & .112 & 2.87 & .982 \\
\hline & 2 & 1,074 & 20.88 & & 2.68 & & 1,388 & 20.60 & & 2.85 & \\
\hline Age 18 & 1 & 1,253 & 21.32 & .479 & 2.57 & .098 & 826 & 21.00 & .286 & 2.82 & .170 \\
\hline & 2 & 1,253 & 21.33 & & 2.49 & & 812 & 20.81 & & 2.74 & \\
\hline Age 19 & 1 & 639 & 21.66 & .513 & 2.51 & .900 & 717 & 21.00 & .892 & 2.76 & .300 \\
\hline & 2 & 607 & 21.59 & & 2.59 & & 702 & 20.95 & & 2.83 & \\
\hline Age 20-29 & 1 & 2,890 & 23.09 & .010 & 2.96 & .554 & 3,488 & 21.85 & .010 & 3.69 & .340 \\
\hline & 2 & 2,878 & 22.94 & & 2.97 & & 3,478 & 21.73 & & 3.57 & \\
\hline Age 30-39 & 1 & 2,305 & 24.65 & .461 & 3.39 & .215 & 3,378 & 22.86 & .712 & 4.03 & .309 \\
\hline & 2 & 2,290 & 24.52 & & 3.30 & & 3,349 & 22.85 & & 4.07 & \\
\hline Age 40-49 & 1 & 1,420 & 25.44 & .137 & 3.59 & .042 & 1,886 & 23.75 & .676 & 4.20 & .428 \\
\hline & 2 & 1,355 & 25.25 & & 3.33 & & 1,844 & 23.77 & & 4.33 & \\
\hline Age 50-59 & 1 & 1,038 & 25.43 & .668 & 3.21 & .523 & 1,601 & 24.65 & .384 & 4.30 & .368 \\
\hline & 2 & 1,029 & 25.56 & & 3.18 & & 1,609 & 24.55 & & 4.13 & \\
\hline Age 60-69 & 1 & 506 & 25.59 & .852 & 3.20 & .264 & 880 & 25.24 & .168 & 4.26 & .312 \\
\hline & 2 & 494 & 25.73 & & 3.28 & & 878 & 25.02 & & 4.17 & \\
\hline Age 70-79 & 1 & 126 & 24.74 & .925 & 3.20 & .532 & 273 & 24.95 & .675 & 4.30 & .213 \\
\hline & 2 & 117 & 24.90 & & 3.27 & & 268 & 24.58 & & 3.71 & \\
\hline
\end{tabular}

Note: $p$ value $=p$ value for equality of means; $p$ value ${ }^{b}=p$ value for equality of variances; $S D=$ standard deviation.

BMI in twins (Johansson \& Rasmussen, 2001; Pietiläinen et al., 2002). Whitfield et al. (2001) reported that the correlation between birth weight and BMI in adulthood was positive, and the correlation is due to genetic factors and non-shared environmental factors. Gielen et al. (2007) indicated that the factors determining birth order, which is one of twin-specific factors, have a greater influence on birth weight than zygosity, chorionicity, and fusion of the placentas. However, it was not known how the birth order differences change over the life course. We found residual differences in BMI between the first-born and the second- born twins until 12 years of age in boys and girls after adjusting for birth weight. Our findings are in accordance with a previous Dutch study showing that the first-born twins were slightly heavier from 3 to 12 years of age (Silventoinen et al., 2007).

The reasons for the birth order difference in BMI in twins are not clear. It is possible that vascular and placental circumstances are important. Twins offer an opportunity to distinguish between maternal factors (e.g., smoking, alcohol, and total placental weight) affecting both twins and factors unique to each twin, such as individual placental 
TABLE 5

Number of Twin Individuals, Mean and Standard Deviation of Birth Weight $(\mathrm{kg})$ and BMI $\left(\mathrm{kg} / \mathrm{m}^{2}\right)$ by Birth Order, Age, and Sex in Dizygotic Twins

\begin{tabular}{|c|c|c|c|c|c|c|c|c|c|c|c|}
\hline & \multirow[b]{2}{*}{ Birth order } & \multicolumn{5}{|c|}{ Men } & \multicolumn{5}{|c|}{ Women } \\
\hline & & $N$ & Mean & $p$ value $^{a}$ & $S D$ & $p$ value $^{b}$ & $N$ & Mean & $p$ value $^{a}$ & $S D$ & $p$ value $^{b}$ \\
\hline Age 1 & 1 & 5,088 & 17.20 & $<.001$ & 1.39 & .037 & 4,759 & 16.81 & .004 & 1.35 & .728 \\
\hline \multirow[t]{2}{*}{ Age 2} & 1 & 4,184 & 16.57 & $<.001$ & 1.41 & .930 & 3,815 & 16.20 & .006 & 1.38 & .423 \\
\hline & 2 & 4,102 & 16.40 & & 1.40 & & 3,871 & 16.04 & & 1.39 & \\
\hline \multirow[t]{2}{*}{ Age 3} & 1 & 5,407 & 16.03 & .003 & 1.54 & .003 & 5,085 & 15.74 & .010 & 1.53 & .314 \\
\hline & 2 & 5,266 & 15.84 & & 1.47 & & 5,208 & 15.63 & & 1.57 & \\
\hline \multirow[t]{2}{*}{ Age 4} & 1 & 2,993 & 16.01 & .047 & 1.87 & .808 & 2,818 & 15.81 & .044 & 1.89 & .656 \\
\hline & 2 & 2,954 & 15.82 & & 1.89 & & 2,848 & 15.68 & & 1.93 & \\
\hline \multirow[t]{2}{*}{ Age 5} & 1 & 2,349 & 15.33 & .020 & 1.59 & .806 & 2,099 & 15.24 & .049 & 1.68 & .195 \\
\hline & 2 & 2,259 & 15.17 & & 1.60 & & 2,189 & 15.09 & & 1.71 & \\
\hline \multirow[t]{2}{*}{ Age 6} & 1 & 583 & 15.65 & .867 & 2.02 & .153 & 455 & 15.65 & .164 & 2.29 & .574 \\
\hline & 2 & 552 & 15.59 & & 2.21 & & 469 & 15.40 & & 2.22 & \\
\hline \multirow[t]{2}{*}{ Age 7} & 1 & 3,986 & 15.50 & .018 & 1.85 & .077 & 3,877 & 15.59 & .178 & 2.09 & .144 \\
\hline & 2 & 3,981 & 15.35 & & 1.92 & & 3,864 & 15.41 & & 2.03 & \\
\hline Age 8 & 1 & 1,478 & 15.75 & .296 & 2.09 & .625 & 1,279 & 15.96 & .194 & 2.26 & .953 \\
\hline \multirow[t]{2}{*}{ Age 9} & 1 & 1,445 & 16.61 & .660 & 2.61 & .161 & 1,354 & 16.77 & .181 & 2.80 & .765 \\
\hline & 2 & 1,449 & 16.41 & & 2.49 & & 1,316 & 16.58 & & 2.82 & \\
\hline \multirow[t]{2}{*}{ Age 10} & 1 & 3,171 & 16.70 & .060 & 2.43 & .002 & 2,994 & 16.98 & .107 & 2.58 & .422 \\
\hline & 2 & 3,148 & 16.48 & & 2.32 & & 2,973 & 16.77 & & 2.68 & \\
\hline \multirow[t]{2}{*}{ Age 11} & 1 & 2,385 & 17.56 & .326 & 2.77 & .992 & 2,146 & 17.77 & .710 & 3.01 & .465 \\
\hline & 2 & 2,288 & 17.40 & & 2.80 & & 2,153 & 17.65 & & 3.04 & \\
\hline \multirow{2}{*}{ Age 12} & 1 & 3,152 & 18.06 & .237 & 2.99 & .853 & 3,031 & 18.26 & .294 & 3.05 & .391 \\
\hline & 2 & 3,021 & 17.89 & & 2.99 & & 3,048 & 18.02 & & 3.02 & \\
\hline \multirow[t]{2}{*}{ Age 13} & 1 & 1,035 & 18.59 & .875 & 3.25 & .572 & 898 & 18.95 & .853 & 3.35 & .876 \\
\hline & 2 & 965 & 18.52 & & 3.20 & & 896 & 18.85 & & 3.35 & \\
\hline \multirow{2}{*}{ Age 14} & 1 & 2,353 & 19.58 & .315 & 3.24 & .741 & 2,332 & 19.92 & .339 & 3.16 & .539 \\
\hline & 2 & 2,266 & 19.58 & & 3.16 & & 2,370 & 19.70 & & 3.11 & \\
\hline Age 15 & 1 & 1,143 & 20.03 & .106 & 3.28 & .007 & 1,042 & 20.23 & .898 & 3.26 & .911 \\
\hline & 2 & 1,078 & 19.62 & & 2.90 & & 1,013 & 20.24 & & 3.37 & \\
\hline Age 16 & 1 & 1,990 & 20.87 & .290 & 3.03 & .800 & 2,086 & 21.05 & .109 & 3.34 & .046 \\
\hline & 2 & 1,940 & 20.77 & & 3.01 & & 2,090 & 20.75 & & 3.11 & \\
\hline Age 17 & 1 & 2,159 & 21.39 & .644 & 2.85 & .038 & 2,230 & 21.09 & .158 & 2.98 & .500 \\
\hline Age 19 & 1 & 1,044 & 21.91 & .785 & 2.61 & .969 & 1,099 & 21.38 & .212 & 3.05 & .082 \\
\hline & 2 & 1,049 & 21.83 & & 2.67 & & 1,047 & 21.12 & & 2.84 & \\
\hline Age 20-29 & 1 & 4,036 & 23.39 & .398 & 3.04 & .507 & 4,398 & 22.07 & .171 & 3.58 & .040 \\
\hline & 2 & 4,121 & 23.37 & & 3.11 & & 4,270 & 21.82 & & 3.42 & \\
\hline Age 30-39 & 1 & 3,221 & 24.81 & .813 & 3.42 & .987 & 4,120 & 23.19 & .619 & 4.30 & .125 \\
\hline & 2 & 3,351 & 24.75 & & 3.41 & & 3,887 & 23.02 & & 4.17 & \\
\hline Age 40-49 & 1 & 2,403 & 25.48 & .932 & 3.35 & .553 & 2,877 & 24.07 & .929 & 4.23 & .975 \\
\hline & 2 & 2,411 & 25.39 & & 3.40 & & 2,775 & 23.99 & & 4.25 & \\
\hline Age 50-59 & 1 & 2,678 & 25.69 & .970 & 3.35 & .673 & 3,261 & 24.75 & .525 & 4.00 & .065 \\
\hline & 2 & 2,634 & 25.63 & & 3.28 & & 3,086 & 24.53 & & 3.89 & \\
\hline Age 60-69 & 1 & 1,265 & 25.49 & .897 & 3.19 & .595 & 1,560 & 25.15 & .769 & 4.19 & .373 \\
\hline & 2 & 1,276 & 25.64 & & 3.29 & & 1,532 & 25.07 & & 4.09 & \\
\hline Age 70-79 & 1 & 310 & 25.34 & .909 & 3.35 & .279 & 435 & 24.99 & .905 & 3.86 & .610 \\
\hline & 2 & 329 & 25.31 & & 3.20 & & 390 & 24.87 & & 4.03 & \\
\hline
\end{tabular}

Note: $p$ value ${ }^{a}=p$ value for equality of means; $p$ value ${ }^{b}=p$ value for equality of variances; $S D=$ standard deviation.

weight and site of the insertion of the umbilical cord. Gielen et al. (2007) reported that the individual placental weight has a stronger association with birth weight than the total placental weight. This suggests that the unique factors are more important than the maternal factors. While placental factors appear to be important, consideration of chorionicity is also necessary.

There are three types of MZ twins based on chorionicity. $\mathrm{MZ}$ twins can either share one chorion and one amnion, each twin can have own amnion, or MZ twins can, like all DZ twins, each have their own chorion and amnion. Shar- ing the same chorion could create either a more similar or a more dissimilar prenatal environment (van Beijsterveldt et al., 2015). Kent et al. (2011) reported that monochorionic twins had higher rates of marginal and velamentous placental cord insertion, and non-central cord insertion contributed to birth weight discordance in monochorionic twin pregnancies. Antoniou et al. (2011), who examined the genetic and environmental etiology of the umbilical cord in a large population of twins, indicated that partly genetic and unique environmental factors influence a number of the morphological characteristics of the overall umbilical 


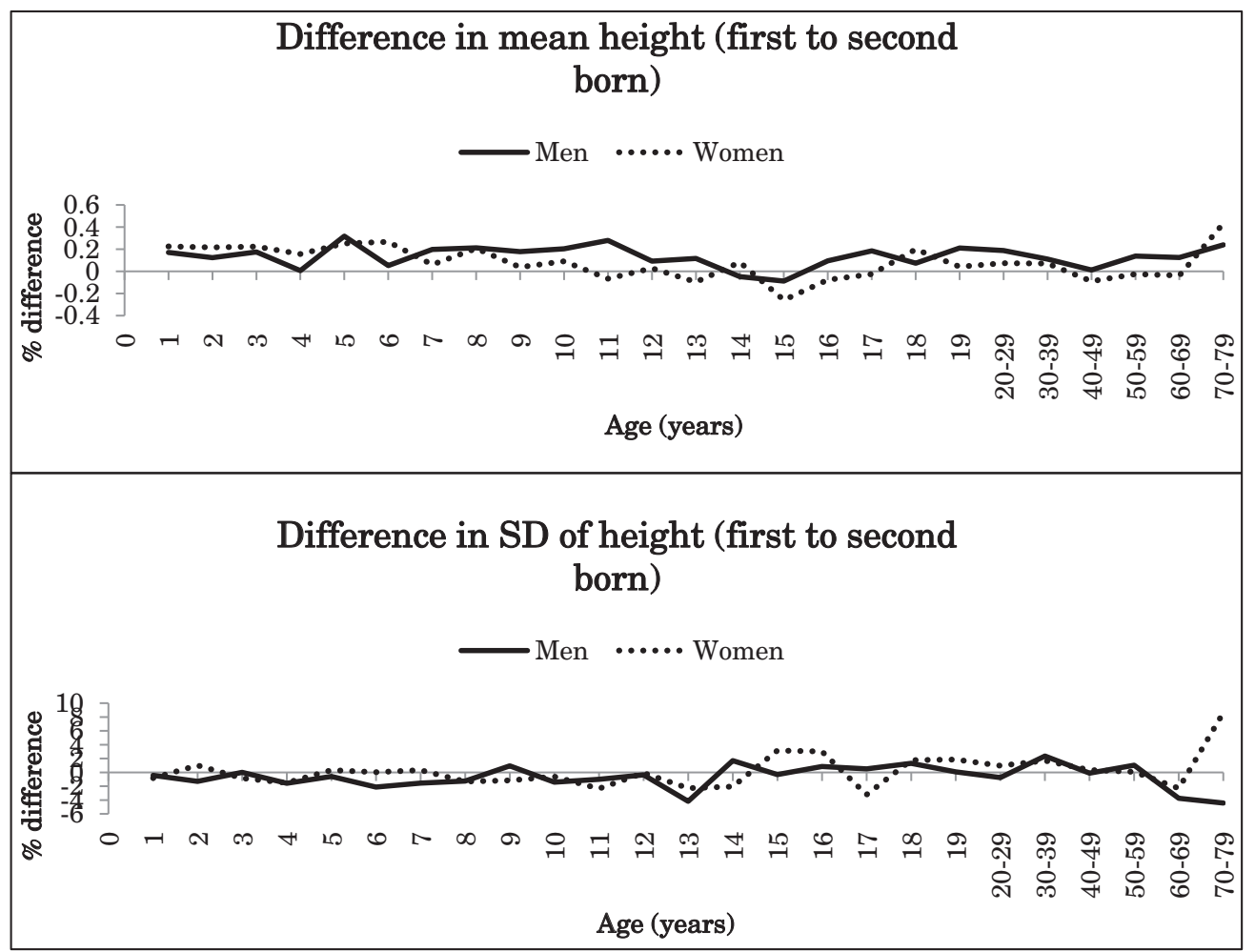

\section{FIGURE 1}

Mean and standard deviation differences (\%) in height between first- and second-born twins across ages.

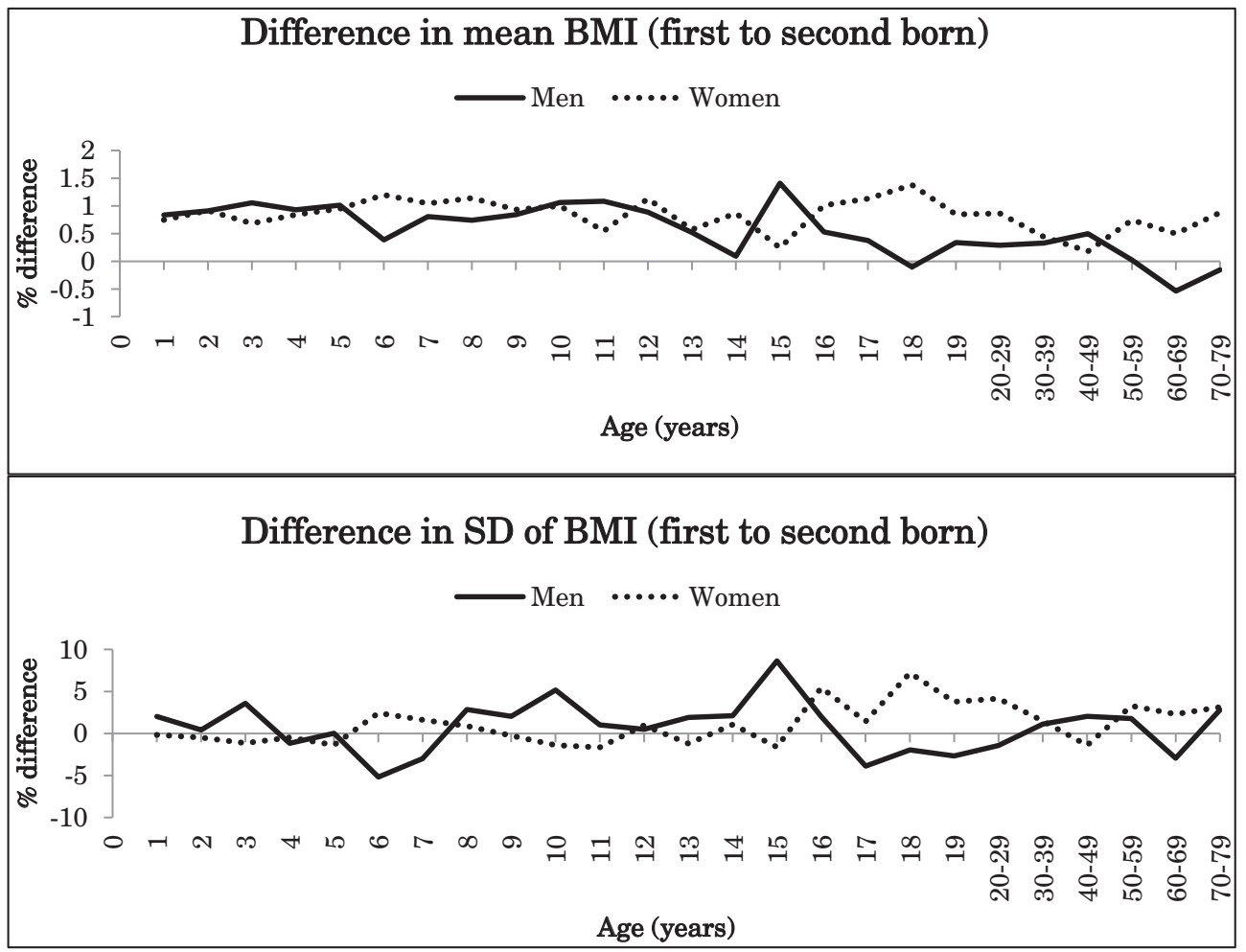

FIGURE 2

Mean and standard deviation differences (\%) in BMI between first- and second-born twins across ages. 
TABLE 6

Fixed Effects Regression Coefficients for the Association Of Birth Order With Height and BMI

\begin{tabular}{|c|c|c|c|c|c|c|c|c|c|}
\hline & & \multicolumn{4}{|c|}{ Height } & \multicolumn{4}{|c|}{$\mathrm{BMI}$} \\
\hline & & \multicolumn{2}{|c|}{ Model 1} & \multicolumn{2}{|c|}{ Model 2} & \multicolumn{2}{|c|}{ Model 1} & \multicolumn{2}{|c|}{ Model 2} \\
\hline & & B & $p$ value & B & $p$ value & B & $p$ value & B & $p$ value \\
\hline \multirow[t]{25}{*}{ Men } & Age 1 & -0.14 & .004 & -0.02 & .565 & -0.15 & $<.001$ & -0.10 & $<.001$ \\
\hline & Age 2 & -0.10 & .120 & 0.00 & .980 & -0.16 & $<.001$ & -0.11 & $<.001$ \\
\hline & Age 3 & -0.18 & .008 & -0.09 & .162 & -0.15 & $<.001$ & -0.12 & $<.001$ \\
\hline & Age 4 & -0.07 & .510 & 0.00 & .978 & -0.11 & .005 & -0.08 & .025 \\
\hline & Age 5 & -0.30 & .017 & -0.17 & .167 & -0.16 & $<.001$ & -0.11 & .005 \\
\hline & Age 6 & -0.01 & .952 & 0.13 & .510 & -0.03 & .635 & 0.00 & .981 \\
\hline & Age 7 & -0.20 & .045 & -0.12 & .238 & -0.13 & .001 & -0.10 & .004 \\
\hline & Age 8 & -0.21 & .169 & -0.11 & .455 & -0.10 & .062 & -0.06 & .250 \\
\hline & Age 9 & -0.10 & .572 & -0.03 & .852 & -0.07 & .376 & -0.04 & .584 \\
\hline & Age 10 & -0.36 & .008 & -0.24 & .064 & -0.16 & .003 & -0.13 & .015 \\
\hline & Age 11 & -0.29 & .089 & -0.19 & .251 & -0.17 & .015 & -0.14 & .044 \\
\hline & Age 12 & -0.07 & .678 & 0.03 & .839 & -0.18 & .004 & -0.15 & .020 \\
\hline & Age 13 & -0.16 & .658 & -0.08 & .813 & -0.08 & .498 & -0.04 & .708 \\
\hline & Age 14 & 0.04 & .895 & 0.11 & .699 & -0.08 & .415 & -0.05 & .608 \\
\hline & Age 15 & 0.03 & .932 & 0.09 & .825 & -0.29 & .042 & -0.28 & .058 \\
\hline & Age 16 & -0.03 & .900 & 0.05 & .845 & -0.16 & .172 & -0.13 & .249 \\
\hline & Age 17 & -0.28 & .239 & -0.19 & .411 & -0.05 & .663 & -0.04 & .735 \\
\hline & Age 18 & -0.29 & .135 & -0.10 & .607 & -0.07 & .475 & -0.04 & .638 \\
\hline & Age 19 & -0.21 & .536 & -0.02 & .962 & -0.11 & .477 & -0.09 & .563 \\
\hline & Age 20-29 & -0.30 & .068 & -0.12 & .447 & -0.08 & .341 & -0.07 & .445 \\
\hline & Age 30-39 & -0.59 & .095 & -0.39 & .257 & 0.06 & .771 & 0.10 & .616 \\
\hline & Age 40-49 & 0.17 & .770 & 0.22 & .697 & -0.18 & .646 & -0.17 & .660 \\
\hline & Age $50-59$ & 0.10 & .917 & 0.13 & .886 & -0.01 & .990 & -0.01 & .990 \\
\hline & Age 60-69 & -0.35 & .795 & -0.33 & .784 & -0.56 & .571 & -0.56 & .577 \\
\hline & Age 70-79 & -4.00 & .753 & -3.88 & .807 & 1.58 & .691 & 1.88 & .698 \\
\hline \multirow[t]{25}{*}{ Women } & Age 1 & -0.13 & .005 & 0.00 & .970 & -0.13 & $<.001$ & -0.07 & .002 \\
\hline & Age 2 & -0.15 & .015 & 0.00 & .959 & -0.14 & $<.001$ & -0.08 & .002 \\
\hline & Age 3 & -0.18 & .007 & -0.08 & .185 & -0.12 & $<.001$ & -0.09 & $<.001$ \\
\hline & Age 4 & -0.11 & .288 & -0.05 & .618 & -0.15 & $<.001$ & -0.13 & .002 \\
\hline & Age 5 & -0.24 & .056 & -0.12 & .330 & -0.15 & $<.001$ & -0.11 & .008 \\
\hline & Age 6 & -0.35 & .188 & -0.13 & .628 & -0.18 & .033 & -0.11 & .204 \\
\hline & Age 7 & -0.19 & .048 & -0.12 & .223 & -0.13 & .001 & -0.10 & .006 \\
\hline & Age 8 & -0.35 & .031 & -0.18 & .273 & -0.18 & .003 & -0.11 & .059 \\
\hline & Age 9 & -0.06 & .742 & 0.07 & .668 & -0.16 & .046 & -0.11 & .190 \\
\hline & Age 10 & -0.15 & .235 & -0.04 & .729 & -0.18 & .001 & -0.13 & .016 \\
\hline & Age 11 & -0.04 & .820 & 0.01 & .972 & -0.09 & .208 & -0.07 & .306 \\
\hline & Age 12 & -0.18 & .269 & -0.12 & .450 & -0.17 & .007 & -0.14 & .030 \\
\hline & Age 13 & -0.03 & .925 & 0.07 & .833 & -0.12 & .344 & -0.09 & .504 \\
\hline & Age 14 & -0.25 & .191 & -0.17 & .369 & -0.20 & .033 & -0.18 & .053 \\
\hline & Age 15 & 0.17 & .588 & 0.32 & .293 & -0.11 & .506 & -0.08 & .630 \\
\hline & Age 16 & -0.08 & .697 & 0.02 & .924 & -0.24 & .036 & -0.21 & .066 \\
\hline & Age 17 & -0.12 & .538 & -0.01 & .951 & -0.19 & .045 & -0.17 & .071 \\
\hline & Age 18 & -0.32 & .226 & -0.15 & .571 & -0.28 & .047 & -0.24 & .081 \\
\hline & Age 19 & -0.01 & .980 & 0.10 & .728 & -0.21 & .180 & -0.18 & .245 \\
\hline & Age 20-29 & -0.20 & .214 & -0.07 & .647 & -0.18 & .097 & -0.16 & .159 \\
\hline & Age 30-39 & -0.16 & .457 & -0.01 & .953 & -0.11 & .475 & -0.09 & .565 \\
\hline & Age 40-49 & 0.04 & .914 & 0.10 & .790 & 0.08 & .778 & 0.08 & .788 \\
\hline & Age 50-59 & -0.25 & .564 & -0.17 & .700 & 0.05 & .889 & 0.04 & .921 \\
\hline & Age 60-69 & 0.22 & .675 & 0.40 & .438 & 0.09 & .833 & 0.12 & .802 \\
\hline & Age $70-79$ & -0.73 & .554 & -0.41 & .736 & 0.00 & .999 & 0.08 & .940 \\
\hline
\end{tabular}

Note: $\mathrm{B}=$ Unstandardized regression coefficient; Model $1=$ Unadjusted; Model 2 = Adjusted for birth weight.

cord development. Thus, even in the very early stages of life, twins can experience unique environmental influences (Antoniou et al., 2011). Unfortunately, our database does not have information on chorionicity, which is only gathered reliably in a few cohorts.

The birth order of twins is determined in early pregnancy, and the first twin at the beginning of pregnancy intrinsically remains in this position (Bronshtein et al., 1998). However, the relationship between the amniotic sac and the cervix, which remains relatively constant throughout gestation, may change near term or during labor in about $10 \%$ of twin pairs discordant for sex, leading to a change in the anticipated twin order (Bronshtein et al., 1998). Since we did not find the interaction effects between birth order and zygosity, potential prenatal environmental differences between MZ and DZ twins do not seem to modify the birth order differences in BMI or height. However, we observed that birth order effects on BMI appear to last longer in MZ twins than in DZ twins, which may reflect the differences in chorionicity. The differences of intrauterine environment between the first-born and the second-born twins need more detailed research. 
Birth order differences have been analyzed previously for perinatal and neonatal outcomes. Previous studies (Armson et al., 2006; Sheay et al., 2004; Smith et al., 2002, 2005, 2007) have reported an increased risk of perinatal death of secondborn compared with first-born twins. It has been proposed that this may be mainly a problem of more stillbirths in the second twins (Smith et al., 2002). Luo et al. (2014) reported that perinatal mortality risk differences in secondborn versus first-born twins depended on their relative birth size, and vaginal delivery at term was associated with a substantially greater risk of perinatal mortality in second twins. These early deaths would have resulted in such pairs not being included in our database.

With regard to neonatal morbidity, the studies of Hacking et al. (2001) and Donovan et al. (1998) both found that second-born twins have increased risk for respiratory distress syndrome. Shinwell et al. (2004) reported that very low birth weight $(<1500 \mathrm{~g})$ second-born twins were at increased risk for acute and chronic lung disease and neonatal mortality, irrespective of mode of delivery. Moreover, Marttila et al. (2004), who analyzed respiratory distress syndrome by gestational age in singletons, first-born , and second-born twins, indicated that first-born twins had a significantly lower incidence of respiratory distress syndrome compared with second-born twins and singletons, except at less than 28 weeks of gestation. By being delivered by the same mother at the same time and gestational age, these factors cannot influence postnatal difference in growth, perinatal mortality, and neonatal morbidity risk between the second-born and the first-born twins. So, any such differences are likely to be attributable to birth weight, fetal growth, and intrauterine environment. Our study suggests that the impact of early morbidity, to the degree that it is indexed by birth order, is limited in time to early childhood, and more so on BMI than height.

The major strength of the present study is the large sample size of our international database of twin cohorts, with height and weight measures covering almost the whole lifespan. However, a limitation is that countries or geographical regions are not equally represented, and the database is heavily weighted toward Caucasian populations. Accordingly, we could not study in detail possible ethnic differences in birth order differences. In addition, the number of twin participants in the oldest age groups is small. Multiple testing may have resulted in false-positive differences between the first-born and the second-born twins. However, mean values showed a consistent pattern across age and sex groups in both $\mathrm{MZ}$ and DZ twins, which provides considerable robustness to the results. Finally, a large majority of height, weight and birth order measures are self or maternally reported. This probably increases random error, which leads to decreasing effect sizes. Our results may thus be underestimations of the real birth order differences.

In conclusion, the first-born twins had a greater BMI and are slightly taller than the second-born twins. Birth order showed a significant association with BMI before 12 years of age. However, in generally, the differences in BMI and height between first-born and second-born twins were very modest even in early childhood. Adjustment for birth weight reduced the birth order differences but did not fully remove them for BMI. Evidence that birth order affects variances of height and BMI was limited.

\section{Acknowledgments}

The Australian Twin Registry is supported by a Centre of Research Excellence (grant ID 1079102) from the National Health and Medical Research Council administered by the University of Melbourne. The Boston University Twin Project is funded by grants (\#R01 HD068435 \#R01 MH062375) from the National Institutes of Health to K. Saudino. The Carolina African American Twin Study of Aging (CAATSA) was funded by a grant from the National Institute on Aging (grant 1RO1-AG13662-01A2) to K. E. Whitfield. Data collection and analyses in Finnish twin cohorts have been supported by ENGAGE - European Network for Genetic and Genomic Epidemiology, FP7HEALTH-F4-2007, grant agreement number 201413, National Institute of Alcohol Abuse and Alcoholism (grants AA-12502, AA-00145, and AA-09203 to R J Rose, the Academy of Finland Center of Excellence in Complex Disease Genetics (grant numbers: 213506, 129680), and the Academy of Finland (grants 100499, 205585, 118555, $141054,265240,263278$, and 264146 to J Kaprio). Gemini was supported by a grant from Cancer Research UK (C1418/A7974). Guangzhou Twin Eye Study is supported by National Natural Science Foundation of China (grant \#81125007). Anthropometric measurements of the Hungarian twins were supported by Medexpert Ltd., Budapest, Hungary. Korean Twin-Family Register was supported by the Global Research Network Program of the National Research Foundation (NRF 2011-220-E00006). Longitudinal Israeli Study of Twins was funded by the Starting Grant no. 240994 from the European Research Council (ERC) to Ariel Knafo. The Michigan State University Twin Registry has been supported by Michigan State University, as well as grants R01-MH081813, R01-MH0820-54, R01-MH092377-02, R21-MH070542-01, R03-MH6385101 from the National Institute of Mental Health (NIMH), R01-HD066040 from the Eunice Kennedy Shriver National Institute for Child Health and Human Development (NICHD), and 11-SPG-2518 from the MSU Foundation. The content of this manuscript is solely the responsibility of the authors and does not necessarily represent the official views of the NIMH, the NICHD, or the National Institutes of Health. PETS was supported by grants from the Australian National Health and Medical Research Council (grant numbers 437015 and 607358 to JC, and RS), the Bonnie Babes Foundation (grant number BBF20704 to JMC), the Financial Markets Foundation for Children 
(grant no. 032-2007 to JMC), and by the Victorian Government's Operational Infrastructure Support Program. The Quebec Newborn Twin Study acknowledges financial support from the Fonds Québécois de la Recherche sur la Société et la Culture, the Fonds de la Recherche en Santé du Québec, the Social Science and Humanities Research Council of Canada, the National Health Research Development Program, the Canadian Institutes for Health Research, Sainte-Justine Hospital's Research Center, and the Canada Research Chair Program (Michel Boivin). South Korea Twin Registry is supported by National Research Foundation of Korea (NRF-371-2011-1 B00047). The Twins Early Development Study (TEDS) is supported by a program grant (G0901245) from the UK Medical Research Council and the work on obesity in TEDS is supported in part by a grant from the UK Biotechnology and Biological Sciences Research Council (31/D19086). The West Japan Twins and Higher Order Multiple Births Registry was supported by Grant-in-Aid for Scientific Research (B) (grant number 15H05105) from the Japan Society for the Promotion of Science. The Murcia Twin Registry is supported by Fundación Séneca, Regional Agency for Science and Technology, Murcia, Spain (08633/PHCS/08, 15302/PHCS/10 \& 19479/PI/14) and Ministry of Science and Innovation, Spain (PSI2009-11560 \& PSI2014-56680-R). The CODATwins project is supported by Academy of Finland (\#266592).

\section{References}

Ananth, C. V., Vintzileos, A. M., Shen-Schwarz, S., Smulian, J. C., \& Lai, Y. L. (1998). Standards of birth weight in twin gestations stratified by placental chorionicity. Obstetrics \& Gynecology, 91, 917-924.

Antoniou, E. E., Derom, C., Thiery, E., Fowler, T., Southwood, T. R., \& Zeegers, M. P. (2011). The influence of genetic and environmental factors on the etiology of the human umbilical cord: The east flanders prospective twin survey. Biology of Reproduction, 85, 137-143.

Armson, B. A., O’Connell, C., Persad, V., Joseph, K. S., Young, D. C., \& Baskett, T. F. (2006). Determinants of perinatal mortality and serious neonatal morbidity in the second twin. Obstetrics \& Gynecology, 108, 556-564.

Barker, D. J. P. (1998). Mothers, babies and health in later life. Edinburgh: Churchill Livingstone.

Bleker, O. P., Breur, W., \& Huidekoper, B. L. (1979). A study of birth weight, placental weight and mortality of twins as compared to singletons. British Journal of Obstetrics and Gynaecology, 86, 111-118.

Brodsky, D., \& Christou, H. (2004). Current concepts in intrauterine growth restriction. Journal of Intensive Care Medicine, 19, 307-319.

Bronshtein, M., Bar-Have, I., Ben-Rafeal, Z., Orvieto, R., Ofir, H., \& Itskovitz, J. (1998). Twin gestation: Is there a correlation $\mathrm{n}$ between the location of the gestational sacs at the beginning of pregnancy, and the order of delivery. European Journal of Obstetrics \& Gynecology, 108, 556-564.
Buckler, J. M., \& Green, M. (2008). The growth of twins between the ages of 2 and 9 years. Annals of Human Biology, 35, 75-92.

Daw, E., \& Walker, J. (1975). Biological aspects of twin pregnancy in Dundee. British Journal of Obstetrics and Gynaecology, 82, 29-34.

Donovan, E. F., Ehrenkrantz, R. A., Shankaran, S., Stevenson, D. K., Wright, L. L., Younes, N., .. Papile, L. A. (1998). Outcomes of very low birth weight twins cared for in the national institute of child health and human development neonatal research network's intensive care units. American Journal of Obstetrics \& Gynecology, 179, 742749.

Gielen, M. L. P, Derom, C., Loos, R. J. F., Derom, R., \& Vlietinck, R. (2006). Curves of placental weights of live born twins. Twin Research and Human Genetics, 9, 664672.

Gielen, M. L. P, Lindsey, P., Derom, C., Loos, R. J. F., Derom, R., Nijhuis, J. G., \& Vlietinck, R. (2007). Twin birth weight standards. Neonatology, 92, 164-173.

Gielen, M., Derom, C., Derom, R., Vietinck, R., \& Zeegers, M. P. (2009). Can birthweight discordancy within monozygotic twin pairs be used as an indicator of chorionicity? Twin Research and Human Genetics, 12, 169-174.

Glinianaia, S. V., Skjaerven, R., \& Magnus, P. (2000). Birth weight percentiles by gestational age in multiple births: A population-based study of Norwegian twins and triplets. Acta Obstetricia et Gynecologica Scandinavica, 79, 450-458.

Gruenwald, P. (1970). Environmental influences on twins apparent at birth. A preliminary study. Biology of the Neonate, 15, 79-93.

Hacking, D., Watkins, A., Fraser, S., Wolfe, R., \& Nolan, T. (2001). Respiratory distress syndrome and birth order in premature twins. Archives of Disease in Childhood - Fetal and Neonatal Edition, 84, F117-121.

Heinonen, S., Ryynanen, M., Kirkinen, P., \& Saarikoski, S. (1996). Perinatal diagnostic evaluation of velamentous umbilical cord insertion: Clinical, doppler, and ultrasonic findings. Obstetrics \& Gynecology, 87, 112-117.

Iachine, I., Petersen, H. C., \& Kyvik, K. O. (2010). Robust tests for the equality of variances for clustered data. Journal of Statistical Computation and Simulation, 80, 365-377.

Jelenkovic, A., Yokoyama, Y., Sund, R., Honda, C., Bogl, L. H., Aaltonen, S., ... Silventoinen, K. (2015). Zygosity differences in height and body mass index of twins from infancy to old age: A study of the CODATwins project. Twin Research and Human Genetics, 4, 1-14.

Johansson, M., \& Rasmussen, F. (2001). Birthweight and body mass index in young adulthood: The Swedish young male twins study. Twin Research, 4, 400-405.

Kent, E. M., Breathnach, F. M., Gillan, J. E., McAuliffe, F. M., Geary, M. P., Daly, S., ... Malone, F. D. (2011). Placental cord insertion and birthweight discordance in twin pregnancies: Results of the national prospective ESPRiT Study. American Journal of Obstetrics and Gynecology, 205, 376.e17.

Loos, R. J., Derom, C., Derom, R., \& Vlietinck, R. (2005). Determinants of birthweight and intrauterine growth in 
liveborn twins. Paediatric and Perinatal Epidemiology, 19(Suppl. 1), 15-22.

Luke, B., Minogue, J., Witter, F. R., Keith, L. G., \& Johnson, T. R. (1993). The ideal twin pregnancy: Patterns of weight gain, discordancy, and length of gestation. American Journal of Obstetrics and Gynecology, 169, 588597.

Luo, Z. C., Ouyang, F., Zhang, J., \& Klebanoff, M. (2014). Perinatal mortality in second- vs firstborn twins: A matter of birth size or birth order?. American Journal of Obstetrics and Gynecology, 211, 153.e1-8.

Marttila, R., Kaprio, J., \& Hallman, M. (2004). Respiratory distress syndrome in twin infants compared with singletons. American Journal of Obstetrics and Gynecology, 191, 271276.

Naeye, R. L., Benirschke, K., Hagstrom, J. W., \& Marcus, C. C. (1966). Intrauterine growth of twins as estimated from liveborn birth-weight data. Pediatrics, 37, 409-416.

Pietiläinen, K. H., Kaprio, J., Rasanen, M., Rissanen, A., \& Rose, R. J. (2002). Genetic and environmental influences on the tracking of body size from birth to early adulthood. Obesity Research, 10, 875-884.

Sheay, W., Ananth, C. V., \& Kinzler, W. L. (2004). Perinatal mortality in first- and second-born twins in the United States. Obstetrics \& Gynecology, 103, 63-70.

Shinwell, E. S., Blickstein, I., Lusky, A., \& Reichman, B. (2004). Effect of birth order on neonatal morbidity and mortality, among very low birthweight twins: A population based study. Archives of Disease in Childhood - Fetal and Neonatal Edition, 89, F145-F148.

Silventoinen, K., Bartels, M., Posthuma, D., Estourgie-van Burk, G. F., Willemsen, G., van Beijsterveldt, T. C., \& Boomsma, D. I. (2007). Genetic regulation of growth in height and weight from 3 to 12 years of age: A longitudinal study of Dutch twin children. Twin Research and Human Genetics, 10, 354-363.

Silventoinen, K., Jelenkovic, A., Sund, R., Honda, C., Bogl, L. H., Aaltonen, S., .. K Kaprio, J. (2015). A cohort descrip- tion of COllaborative project of development of anthropometrical measures in Twins (CODATwins) to study macroenvironmental variation in genetic and environmental effects on anthropometric traits. Twin Research and Human Genetics, 18, 348-360.

Silventoinen, K., Pietilainen, K. H., Tynelius, P., Sørensen, T. I., Kaprio, J., \& Rasmussen, F. (2007). Genetic and environmental factors in relative weight from birth to age 18: The Swedish young male twins study. International Journal of Obesity, 31, 615-621.

Smith, G. C., Fleming, K. M., \& White, I. R. (2007). Birth order of twins and risk of perinatal death related to delivery in England, Northern Ireland, and wales, 1994-2003: Retrospective cohort study. BMJ, 334, 576.

Smith, G. C., Pell, J. P., \& Dobbie, R. (2002). Birth order, gestational age, and risk of delivery related perinatal death in twins: Retrospective cohort study. BMJ, 325, 1004.

Smith, G. C., Shah, I., White, I. R., Pell, J. P., \& Dobbie, R. (2005). Mode of delivery and the risk of delivery-related perinatal death among twins at term: A retrospective cohort study of 8073 births. BJOG, 112, 1139-1144.

Soucie, J. E., Yang, Q., Wen, S. W., Fung, K. F., \& Walker, M. (2006). Neonatal mortality and morbidity rates in term twins with advancing gestational age. American Journal of Obstetrics and Gynecology, 195, 172-177.

Van Baal, G. C. M., \& Boomsma, D. (1998). Etiology of individual differences in birth weight of twins as a function of maternal smoking during pregnancy. Twin Research, 1, 123-130.

van Beijsterveldt, C. E. M., Overbeek, L. I. H., Rozendaal, L., McMaster, M. T. B., Glasner, T. J., Bartels, M., ... Boomsma, D. I. (2015). Chorionicity and heritability estimates from twin studies: The prenatal environment of twins and their resemblance across a large number of traits. Behavior Genetics. Advance online publication.

Whitfield, J. B., Treloar, S. A., Zhu, G., \& Martin, N. G. (2001). Genetic and non-genetic factors affecting birth-weight and adult body mass index. Twin Research, 4, 365-370. 